\title{
Construction of Maker Multimedia Technology for the Course of Sports Marketing
}

\author{
https://doi.org/10.3991/ijet.v12.i09.7488 \\ Ben Niu \\ Beijing Youth Politics College, Beijing, China \\ Fatao Wang $(\bowtie)$ \\ Beijing Union University, Beijing, China \\ wftbldesina.com \\ Aili Qi \\ Guizhou University of Engineering Science, Bijie, China
}

\begin{abstract}
Maker education is a new-type educational mode aiming of training and improving students' innovation ability and transforming students' passive learning into initiative exploration. So far, few researches have been made on the field of maker education for the course of Sports Marketing, and the relevant multimedia technology also has not been completely developed, which poses an undue barrier to the launch of maker education. In this paper, maker education multimedia technology for the course of Sports Marketing is developed based on Blockly frame, applying the theory related to maker education, namely the theory of successful intelligence, in the course of Sports Marketing for the first time, and design the maker education multimedia technology from both function design and process design. Finally, to check the effect of the multimedia technology developed in this paper, we use the multimedia technology in the "sports marketing" course for comparison and verification. Results demonstrate the average scores and the proportion of high scores of the class for which the maker education multimedia platform was implemented in the teaching process of Sports Marketing are superior to that of the class for which the maker education multimedia platform was not implemented. These findings indicate that the technology is greatly helpful to improve students' innovation ability, and is of high promotional value and broad application prospect.
\end{abstract}

Keywords-Sports marketing teaching, multimedia technology, maker education

\section{Introduction}

With the rise of the Internet wave in recent years, maker education has been proposed in many fields. Maker is a generic terms of a group who devote themselves to make use of their own knowledge background and all resources available to them to make innovation and forge ahead out of interest to discover new ideas, invent new 
products and put forward new theories [1]. Maker can help raise the innovation level of our country, and promote our country to transform from "Made in China" into "Designed in China" in the process of economic transition and upgradation. Maker education is a new-type education mode aiming of training and enhancing students' innovation ability [2]. In the process of maker education, abundant online and offline teaching resources that are out of our reach in traditional teaching method are made use of to create a way and channel for students to realize their innovative ideas and opinions. Maker education mainly aims to transform students' passive learning state into active exploration activities. In this process, students will not passively accept knowledge any more, and their innovation ability also can be largely improved [3]. The course of Sports Marketing is a practical course, and the external sports economic environment and situation also keep changing, which requires students to be able to creatively study and apply the knowledge to explain and solve the ever-changing realistic situation [4]. It is impossible to improve students' innovation ability by making students passively accepting theories and knowledge in teaching only. It is helpful to improve students' innovation ability by introducing maker education into the course of Sports Marketing. But, there are few researches on the field of maker education for the course of Sports Marketing, and the relevant multimedia technology has not been fully developed, which poses an undue barrier to the implementation of maker education. In view of this, we have developed maker education multimedia technology for the teaching of Sports Marketing based on the theory of successful intelligence and relevant computer theories.

\section{State of the art}

According to traditional teaching mode and method, stress is laid on the cultivation of students' analytical intelligence. In maker education, however, more focus is laid on the cultivation of students' innovation ability. The function of maker education in developing students' innovation and creative ability has attracted extensive attraction, so that a lot of relevant researches have been made to apply maker education in the teaching process [5].

In researches on theories on maker education, Ageyev [6] suggested we should consider the translating (consuming) character of contemporary education as its problem. It was pointed out that it is impossible to raise the creative ability and forecasting ability under the conditions of appropriating (culture-consuming) education, which could only be solved under the conditions of creative (culture-generating) education. For purpose of this article, the results of experimental education under the conditions of creative education are cited, and good application effect has been achieved. Luo and Zhu [7] applied maker education in computer education, and constructed opensource hardware in which the viewpoints of "hardware development platform" and "cordwood open-source hardware" are held in the mode of maker education, demonstrating the effect of maker education based on open-source hardware on the cultivation of learners' innovation ability by means of experiment from the aspects of learner, teacher, activity, course and project. Zhang [8] applied maker education in teach- 
ing design of college administrative courses, pointed out that course content integration, course content innovation and course module collaboration were the key points of course design of maker education, and put forward a general framework of administrative course design for implementation of maker education. $\mathrm{Lv}$ [9] researched the application of maker education in electronic commerce education, studying the mechanism of maker education influencing the specialty accomplishments and ability of the majors of electronic commerce by means of questionnaire survey, and putting forward measures for the application of maker education in the specialty of electronic commerce on this basis.

In the course of Sports Marketing, maker education becomes more demanding for educators. Firstly, the course of Sports Marketing relates to various different contents, covering specialized knowledge, and also requiring overlapping and integrating knowledge of other subjects. Secondly, innovation appears to be more important to economics courses such as Sports Marketing, for which it is of great significance to make use of the learned theoretical knowledge to guide concrete economics marketing decision. But the spatial and temporal limitations of classroom teaching hinder this target. Hence, more modern teaching technologies and multimedia technologies are needed to assist the implementation of maker education [10]. Moreover, maker education also has its deficiencies. Firstly, maker education has been seldom applied in multimedia teaching, and few people have a good knowledge of the contents and value of maker education. Secondly, slide presentation is widely adopted in maker education. Most slides are embedded with swf files, but the embedded swf files cannot be separately extracted for use, or sparsed, which will reduce the classroom atmosphere and teaching efficiency.

In view of the foregoing background, this paper is intended to study multimedia technology development for maker education via case study of the course of Sports Marketing, with a hope to apply maker education mode in economics and marketing courses well. The innovation points and advantages of this research mainly include: firstly, it is the first time to apply the theory of successful intelligence, a theory on maker education, in the course of Sports Marketing, providing a theoretical basis for the application of maker education in economics and marketing courses; secondly, maker education multimedia technology has been developed according to the characteristics of the course of Sports Marketing in this paper; thirdly, for purpose of this research, a new-type slide file that can be parsed to extract the embedded flash file is applied, which is easy to realize and operate.

\section{Model analysis}

\subsection{Theory of successful intelligence}

A person's intelligence development level decides whether he/she can succeed in career to a large extent. Sternberg divided human intelligence into three parts (see Fig. 1), regarding an individual's intelligence level as the composite of the three parts. 
Analytical intelligence mainly refers to the ability of thinking and solving theoretical problems. The examinations implemented in schools are mainly for inspecting students' analytical intelligence. Creative intelligence refers to the innovation ability of human individuals of making use of their knowledge background and world view to recognize problems, solve problems, invent new products and put forward new theories. Practical intelligence refers to the ability of solving practical problems in daily life. The three parts of intelligence are inseparable, and an individual is more likely to succeed if his/her three parts of intelligence achieve balanced development to reach a high level.

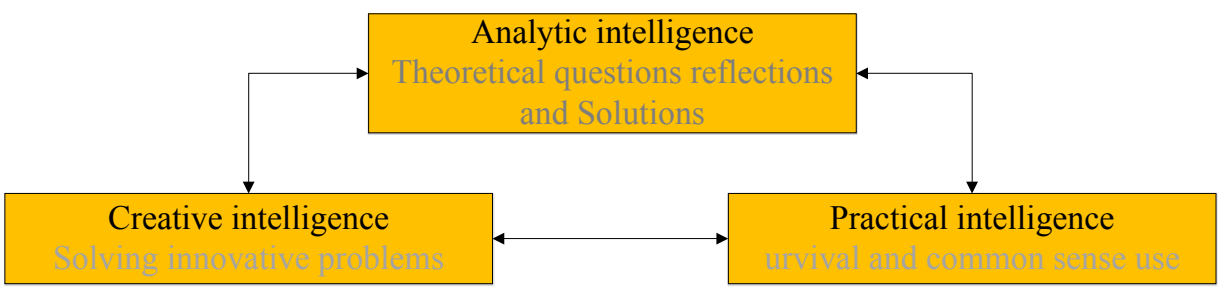

Fig. 1. Frame diagram of the theory of successful intelligence

In the teaching of the course of Sports Marketing, basic theories and knowledge on economics and administration will be imparted to students first. The course of Sports Marketing is a practical course, the external economic environment and administration environment keep changing, and the relevant theories also are constantly developed. The theories applicable before are likely to have become obsolete for the current situation. Hence, students need to study the current situation of the course of Sports Marketing and build a model accordingly, and apply the relevant theories and knowledge background they have learned to solve problems. In this process, students should have certain innovation ability to both apply the relevant theories and knowledge and put forward solutions. The core of maker education is innovation, which aims to train students' innovation ability in various different ways. Therefore, applying maker education in the course teaching of Sports Marketing will help improve students' innovation ability, to promote the balanced and harmonious development of the three parts of students' intelligence.

\subsection{Modularization programming technology}

For purpose of this research, the Blockly programming frame which provides visual programming interface and interface released by Google was adopted. It essentially is a JavaScript base with which graphical interfaces can be generated with the programming language of visualization module. It is an open-source project developed and maintained by Google. It usually runs in Web browser, and also can be used for developing client-side. It links visualization modules together so as to make it easier to generate corresponding codes, and can support the generation of JavaScript code, Python code, PHP or Dart code. 
Blockly provides developer with interfaces for binding code with visualization modules together, so that developer can create personalized module. In this research, visualization modules are designed based on the Blockly programming frame for the course of Sports Marketing, which provides a basis for technological realization for the maker education multimedia technology for the course of Sports Marketing. The process of generating user-defined modules with Blockly mainly consists of two steps. The first step is to define the personalized modules, and the second step is to generate codes in correspondence with the personalized modules.

\section{Construction of maker education multimedia platform for the course of Sports Marketing}

Blockly technology is adopted for the development of the graphic interfaces of the multimedia platform, and Java-based client-side development technology for the development of the backend.

\subsection{Function design}

The maker education multimedia platform developed for the course of Sports Marketing in this research mainly has the following functions, namely model programming function, module customization function and knowledge management function. The model programming function has two sub-functions, namely view and setting of preset module, and visual programming. The knowledge management function also has two sub-functions, namely Sports Marketing knowledge learning, and model example view.

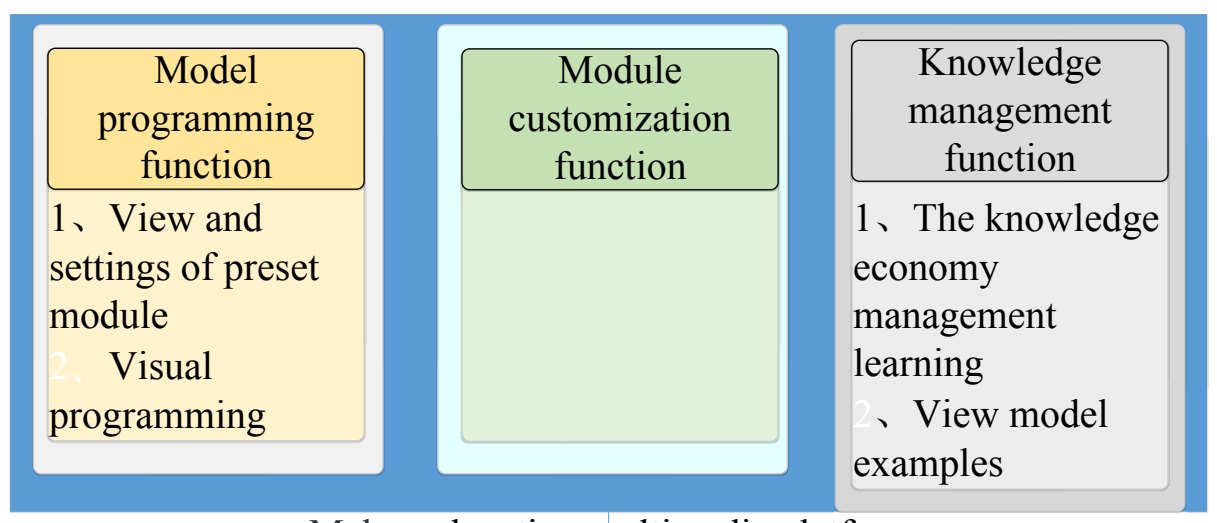

Maker education multimedia platform

Fig. 2. Function structure chart of maker education multimedia platform

View and setting of module. Via this sub-function, user can view the functions provided by some basic modules predefined by teacher, and set the parameters of the 
modules according to the actual problem in the course of Sports Marketing, to make the modules more applicable for problem model.

Module customization. The preset modules in the system cannot apply to all problem models. Thus, via this sub-function, user is provided with the function of defining new modules for building his/her own problem model. The implementation of the module customization sub-function is based on the Blockly technology.

Visual programming module. After entering this module, user can have a maker experience by making use of the visual module programming technology provided by the platform to build a model related to Sports Marketing based on his/her knowledge background, so as to generate a desired program. Besides, this module provides user with a port for viewing program, where the models implemented and stored by the user before are stored.

Sports Marketing knowledge learning. Via this module, student user can view and learn the knowledge related to the course of Sports Marketing. The application of maker education multimedia platform in the teaching of Sports Marketing is as shown in Fig. 3.

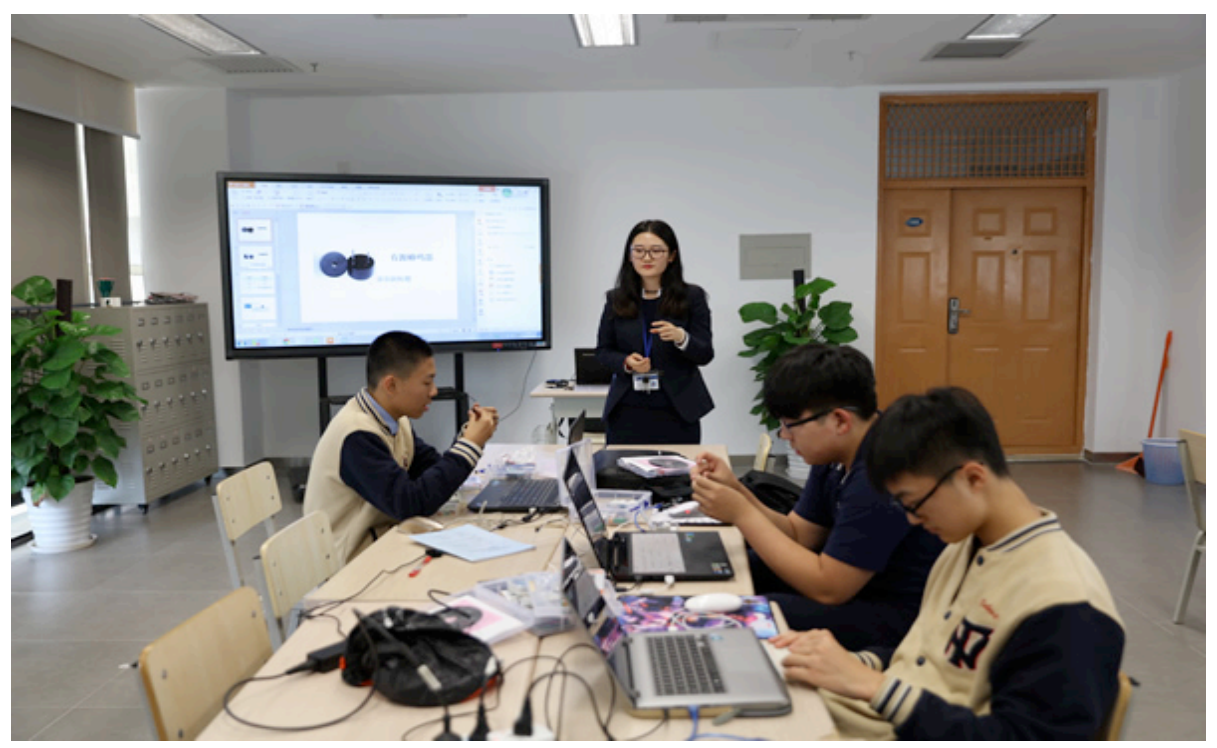

Fig. 3. Interactive display of teacher student interaction in Chinese Universities maker education

Model example view. This module aims to help students have better understanding of and apply the functions provided by the platform. In this module, examples of implementation of functions of the platform are available, which are for guiding student user to use the platform. Figure 4 shows the landing interface of a maker education multimedia platform 


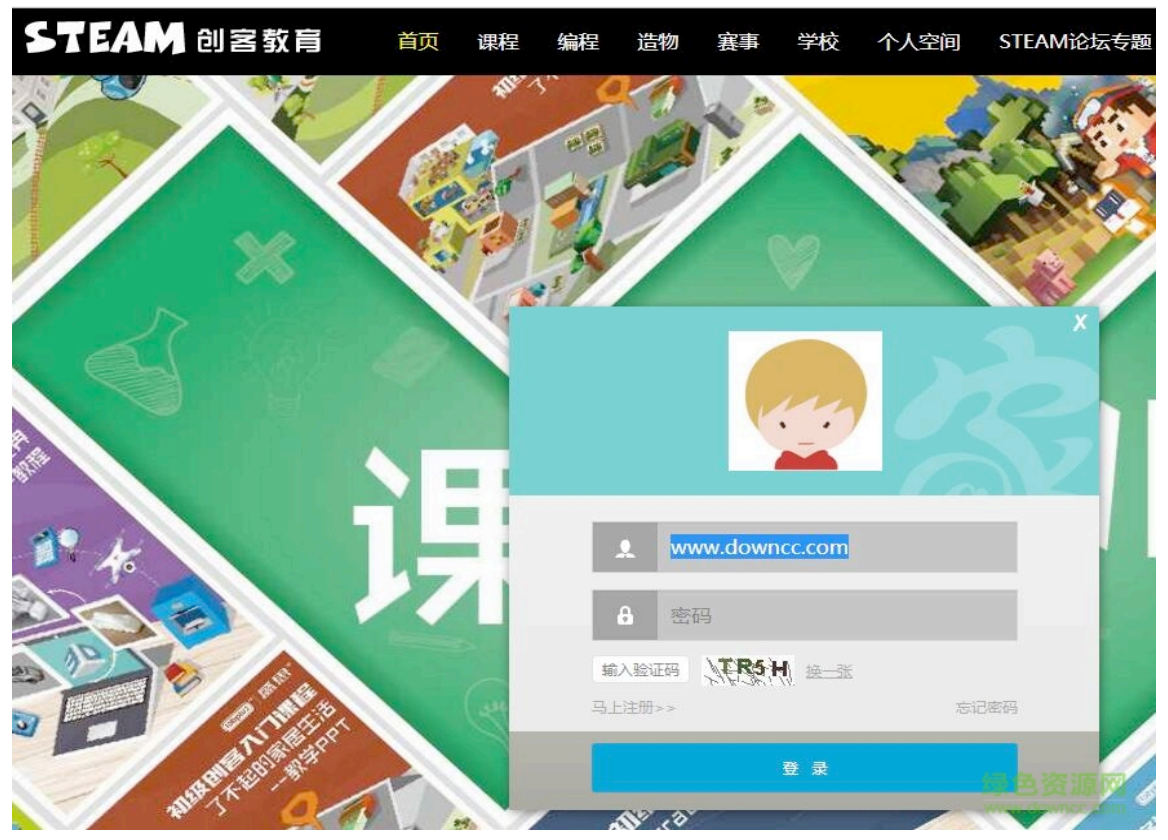

Fig. 4. Login interface of the maker education multimedia platform

\subsection{Flow design}

Student user can implement the model defined by him/her via visual module programming. For every visual module, the corresponding service back-end codes are defined, and the service back-end is linked with the data storage module to realize permanent storage of student user's model. After student user's model has been defined, the platform presents the module service back-end and the program in correspondence with the user model generated based on the permanent storage to the user in accordance with the modules that the model consists of and the parameters set for the model. Please see Fig. 5 for the flow design.

\subsection{Effect evaluation}

For purpose of this experiment, two classes of college students ( 80 students a class) of sports specialty were required to participate in the learning of the course of Sports Marketing. For one class, the maker education multimedia platform developed in this research was implemented.

The experiment was carried out to fulfill two tasks. The first task is to survey the respondents' comments on the multimedia platform developed in this research. To fulfill this task, the maker education multimedia technology developed in this research was applied in the teaching of the course of Sports Marketing of one class, a questionnaire survey and interviews were made on the course learning process and the effect of the technology over the students of this class, and the proportion of each 
item to the total number of respondents was calculated based on the collected questionnaires and the interview results. The second task is to check the effect of the multimedia platform in maker education. To fulfill this task, an innovative question was set (make a plan on implicit marketing in the Beijing Olympics in 2022) to check the ability of modeling and problem solving of the students of the two classes. To this end, the models and solutions put forward by the students were evaluated in accordance with the same criteria, and the results of the students were compared.

The contents of the questionnaire and interview mentioned above and the survey result are as shown in Tab. 1.

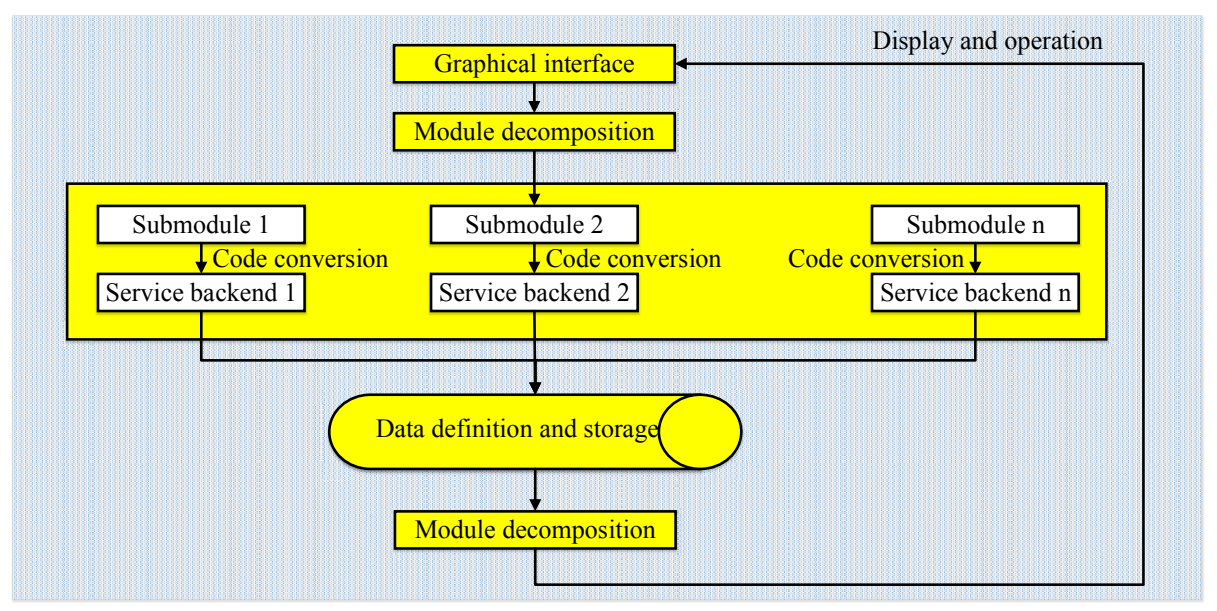

Fig. 5. Flow design diagram of visual programming of the multimedia platform

Table 1. Comments on the multimedia application in maker education of students of sports specialty

\begin{tabular}{|l|c|c|}
\hline \multicolumn{1}{|c|}{ Question } & Subtotal & Proportion \\
\hline I can make use of the software as long as have a certain period to learn it. & 58 & $72.50 \%$ \\
\hline The logic relationship among modules is simple and easy to understand. & 47 & $58.75 \%$ \\
\hline $\begin{array}{l}\text { User should fill in relevant parameters only, without having to learn complicated } \\
\text { programming codes. }\end{array}$ & 45 & $56.25 \%$ \\
\hline I can learn to write some programs by myself. & 12 & $15.00 \%$ \\
\hline Sometimes, I need the help of my teacher in programming. & 36 & $45.00 \%$ \\
\hline It is different from the software I got to know before, which is difficult to master. & 8 & $10.00 \%$ \\
\hline It is kind of complicated to set the parameters. & 0 & $0.00 \%$ \\
\hline I am not familiar with the interfaces. & 12 & $15.00 \%$ \\
\hline I cannot get used to the operation. & 13 & $16.25 \%$ \\
\hline It is complicated to set the parameters. & 0 & $0.00 \%$ \\
\hline I can't understand the modules. & 0 & $0.00 \%$ \\
\hline The program is totally beyond me. & 5 & $6.25 \%$ \\
\hline I can't learn to use it without the teacher's help. & 0 & $0.00 \%$ \\
\hline
\end{tabular}


According to Tab. 1, most students can master the maker education multimedia technology rapidly and apply it in the learning process of the course of Sports Marketing without having to do extra work. This new-type maker education multimedia technology has transformed students from the state of passively accepting knowledge into the state of actively and innovatively learning, which is of high promoting significance to improving students' innovation ability, of high promotional value, and broad application prospect. The average scores and the proportion of high scores of the class for which the maker education multimedia platform was implemented in the teaching process of Sports Marketing are superior to that of the class for which the maker education multimedia platform was not implemented. This suggests that the maker education multimedia platform can help improve students' ability of modeling and problem solving and innovation ability largely.

\section{Conclusions}

In this paper, a maker education multimedia technology is developed for the course of Sports Marketing based on the theory of successful intelligence and the Blockly frame. It is the firs time to apply the theory of successful intelligence in the teaching of the course of Sports Marketing. It provides a theoretical basis for the application of maker education in the course of Sports Marketing. The maker education multimedia technology has been proved to be of good application effect via real application in classroom teaching. The research results indicate that it is feasible to apply the multiple platform of maker education in teaching widely. Firstly, maker education can effectively complement the traditional classroom teaching mode, which is expected to promote knowledge learning and the cultivation of practical ability and creative ability. Besides, the construction of a multimedia platform of maker education should harmonize with the environment, curriculum and teaching reform and cultural construction of school. Secondly, on a multimedia platform of maker education, stress is laid on linkage of knowledge of different subjects, the teaching process has been transformed from passive acceptance into active exploration, it is rejected to directly stuff the ready-made knowledge into students, and efforts are made to create problem situation for students to enable students to think independently and solve problems via cooperation, which can arouse students' learning interest and improve students' ability of problem solving. Thirdly, this platform is implemented based on the theory of successful intelligence, in which importance is attached to improving students' ability of thinking and problem solving, more focus is put on students' individual difference in evaluation, and developmental evaluation is adopted to cover students' acquisition of knowledge, and extend to students' attitude to and enthusiasm for exploration and creation, formation of good learning habit, and development of abilities of problem solving, innovation and cooperation. It is thus clear that the maker education and newtype multiple platform put forward in this research are helpful to improve students' innovation ability, and are of high promotional value and broad application prospect. 


\section{Acknowledgment}

This work was supported in part by the 2017 annual Social Science Youth Talents projects of Beijing Social Science Association (2017QNRC20).

\section{$7 \quad$ References}

[1] Gupta, A. Creative education: disruptive innovation: universities role in enhancing social and economic productivity. Cell, 2014, vol. 59(1), pp. 219-228.

[2] Sheridan, K., Halverson, E.R., Litts, B., et al. Learning in the making: A comparative case study of three makerspaces. Harvard Educational Review, 2014, vol. 84(4), pp. 505-531. https://doi.org/10.17763/haer.84.4.brr34733723j648u

[3] Pritchard, S.M. Building Institutions of Knowledge: Librarianship as a Maker-Space. Portal Libraries \& the Academy, 2014, vol. 14(4), pp. 471-473. https://doi.org/10.1353/ pla.2014.0030

[4] Deng, W.C. Enlightenment of the New Economic Theory in the Sports Marketing. Journal of Beijing Sport University, 2005, vol. 28(7), pp. 877-878.

[5] Rojanapanich, P., Pimpa, N. Creative Education, Globalization and Social Imaginary. Creative Education, 2011, vol. 2(4), pp. 327-332. https://doi.org/10.4236/ce.2011.24046

[6] Ageyev, V. Psychological Foundations of Creative Education. Creative Education, 2012, vol. 3(1), pp. 1-9. https://doi.org/10.4236/ce.2012.31001

[7] Luo, L., Zhu, Z.T. Open Source Hardware $\square$ A Leverage of Maker Education Practice. China Educational Technology, 2015, no. 4, pp. 7-14.

[8] Zhang, M., Xia, X.B., Wu, C.Y. The Design of Management Courses under the Mode of Entrepreneur Education. jiaoyu jiaoxue luntan, 2017, vol. 7, pp. 181-182.

[9] Lv, L., Zhu, Y.Y. A study of creative education for e-commerce Majors. Market Modernization, 2016, vol. 29, pp. 46-47.

[10] Zheng, Y.L. Path Analysis for the Implementation of Maker Education in Colleges and Universities in USA. Education Research, 2015, vol. 15(3), pp. 21-29.

\section{Authors}

Ben Niu is an Assistant Research Fellow in the Beijing Youth Politics College, Beijing 100102, China (niuben4002@sina.com).

Fatao Wang (corresponding author) is an associate professor in the College of Arts and Science, Beijing Union University, Beijing 100101, China (wftbld@sina.com).

Aili Qi is an associate professor in Guizhou University of Engineering Science, Bijie 551700, China. (qiailili@yeah.net).

Article submitted 18 April 2017. Published as resubmitted by the authors 23 June 2017. 